\title{
Evaluating the internalisation of core values at a South African public service organisation
}

\author{
Authors: \\ Susanna M. O'Neil ${ }^{1}$ \\ Andre L. Horne ${ }^{1}$ \\ Affiliations: \\ ${ }^{1}$ Department of Human \\ Resources Management, \\ University of Pretoria, \\ South Africa \\ Correspondence to: \\ Andre Horne \\ Email: \\ horneal@unisa.ac.za \\ Postal address: \\ Private Bag X20, Hatfield \\ 0028, South Africa \\ Dates: \\ Received: 24 Feb. 2011 \\ Accepted: 11 May 2012 \\ Published: 27 Sept. 2012 \\ How to cite this article: \\ O'Neil, S.M., \& Horne, \\ A.L. (2012). Evaluating the \\ internalisation of core values \\ at a South African public \\ service organisation. SA \\ Journal of Human Resource \\ Management/SA Tydskrif vir \\ Menslikehulpbronbestuur, \\ 10(1), Art. \#371, 14 pages. \\ http://dx.doi.org/10.4102/ \\ sajhrm.v10i1.371
}

C 2012. The Authors. Licensee: AOSIS OpenJournals. This work is licensed under the Creative Commons Attribution License.
Orientation: Fully entrenched and internalised organisational values have proved a competitive advantage for many leading organisations. The benefits range from higher profit margins to the improvement of employees' commitment and ethical performance. Nevertheless, the process of value shaping is often no more than a management goal. It is rarely truly internalised by the whole organisation.

Research purpose: This article presents an effort to describe a value internalisation effort within a South African public service organisation as well as the results of a subsequent evaluation to ascertain to what extent those efforts actually led to internalisation throughout the organisation. A set of actions and practices were implemented within the public service organisation; the intent was that they should enhance value internalisation in the organisation. A long-term strategy of value internalisation was followed that focussed mainly on the clear articulation and communication of the values through different communication mediums and platforms, such as road shows and branded value material hand-outs, as well as through extensive value internalisation training.

Motivation for the study: Documentation of value internalisation processes and its evaluation, especially in South African public service organisations is extremely rare. To ensure that public service organisations do not repeat the same mistakes in their value internalisation practices and implementation processes, proper documentation of these processes in the public and research domains are needed. The need for the evaluation of value internalisation programmes should also be propagated as in many instances, programmes are implemented, but the subsequent success thereof is never evaluated.

Research design, approach and method: A survey questionnaire consisting of a 5-point rating scale was developed to measure the extent of value internalisation after the implementation of long-term internalisation strategies. Employees at different levels and in different units of the organisation participated in the survey.

Main findings: Results $(N=941)$ reflected lower than expected mean scores for each value component. In addition, differences in internalisation extent were found between two demographic variables, namely population groupings and organisational units.

Practical/managerial implications: The results of this study confirmed certain shortcomings in value internalisation processes, such as the way values are identified, communicated and reinforced. Knowledge of the latter may help human resource (HR) practitioners to apply more effective value shaping practices.

Contribution/value-add: This study provides specific guidelines that may enable practitioners to evaluate their own value internalisation practices. These guidelines include creating institutional value parity through employee engagement and encouraging leaders to facilitate both the emotional and cognitive interface of value internalisation efforts. Furthermore all leaders in the organisation should be exposed to training and development programmes that address the importance of leaders' own credibility in efforts to institutionalise values within the organisation. The measurement instrument developed for this study may also provide HR practitioners with a means to evaluate the extent of value internalisation in an organisation.

\section{Introduction}

\section{Key focus of this study}

Organisational values are the principles which govern the behaviour or the people in an organisation. They arise out of a group of shared values and beliefs within the organisation and are the basis for the philosophy and activities of the organisation (Askun, Oz \& Askun, 2010; Cambra-Fierro, Polo-Redondo \& Wilson, 2008; Serrat, 2010). They drive all behaviour within the organisation (Agle \& Caldwell, 1999; Brăinianu \& Bălănescu, 2008), and there is some evidence that they may even influence behaviour outside the organisation (Cambra-Fierro et al., 2008). 
Within an organisation, they serve two primary purposes: firstly to motivate employee and organisational behaviour, and secondly to provide a standard against which actions are evaluated (Grojean, Resick, Dickson \& Smith, 2004; Sullivan, Sullivan \& Buffton, 2002).

The benefit of clearly articulated and entrenched organisational values has been established in many scholarly articles. They make a significant difference to the lives of employees, as well as to organisational performance (Posner, Kouzes \& Schmidt, 1985; Posner, 2010; Sullivan et al., 2002). Shared organisational values result in more effective organisational operations (Schein, 1990, p. 84), superior financial results and overall organisational success (Van Lee, Fabish \& McGraw, 2005). Schein (1990) as well as Gruys, Stewart, Goodstein, Bing and Wicks (2008) emphasise profitability as a benefit arising from shared, strong, coherent core values. They are also of the opinion that shared values build onto a strong organisational culture and contribute to increased ethical performance in the organisation. Sullivan et al. (2002) mention that values-led companies outperform companies that are not values-led with regard to growth in revenue, rate of job creation, growth of stock price as well as performance growth and lower turnover. Organisations that are values-driven are therefore more likely to gain a competitive advantage.

All organisations have values by which they operate; these values may be explicit or implicit (Brăinianu \& Bălănescu, 2008). However, to reap the benefits that organisational values bring about, the values need to be clearly articulated as well as integrated in the organisation's heart and mind. This implies that all the employees within an organisation as well as the management should not only know what the organisational values are, but also demonstrate value alignment through their own actions and behaviour. Stated differently, values should be articulated as well as enacted and entrenched in the practices of an organisation (Collins \& Porras, 1994; Speculand \& Chaudhary, 2008). Value-driven transformation in an organisation can only occur if the individuals in the organisation have begun to internalise the organisation's chosen values. Values that are solely a management goal are therefore not seen as an asset to the organisation; they remain an empty banner which are articulated by management only, without any enactment by individual employees (and consequently the organisation as a whole). Values only become an asset when they are translated into behaviours, and all the employees demonstrate these behaviours in a way that influences organisational performance (Van Lee et al., 2005).

Organisational values are usually incorporated into organisation statements, strategic documents and communication media after they had been formulated and defined. Portraying values in writing is not difficult; it is the internalisation of organisational values that seems to be the challenge (Gruys et al., 2008; Speculand \& Chaudhary, 2008). It is this challenge that is the key focus of this study.
The objectives of this study were firstly to describe the value internalisation efforts of a public service organisation in South Africa, and secondly to evaluate the extent to which its specific and intensive value implementation efforts contributed to value internalisation within the different levels of the organisation; in other words, whether it actually filtered through to all the different levels within the organisation. This public service organisation falls within the safety and security industry (e.g. emergency personnel, police, SANDF). The value internalisation strategy focussed mainly on the clear articulation and communication of the values through different communication mediums and platforms, such as road shows and branded value material, as well as through extensive value internalisation training. The question which remained, and which this study aimed to answer, was whether all these efforts filtered through to all the levels within the organisation. Although extensive research has been conducted on the effects and advantages of being a values-driven organisation, little research has focussed on the implementation processes and the actual internalisation of organisational values (Morginson, 2009).

\section{Background to the study}

Organisations face the challenge of establishing congruence between espoused and enacted organisational values. Speculand and Chaudhary $(2008$, p. 324) are of the opinion that 'unfortunately and more often than not, there tends to be a phenomenal gap between identifying Organisational values and actually living them'. Espoused values are those that are clearly illustrated, stated and communicated as a reference for behaviour and performance (Travaglione, McShane, O' Neill \& Hancock, 2009). They include the core beliefs, principles and values that the organisation has officially accepted and seeks to act upon in the course of day-to-day actions. Although espoused values may be embedded in an organisation's vision, mission, strategy and core value system, they are often far removed from and inconsistent with behavioural practices observable within the organisation (McGaw \& Fabish, 2006; Serrat, 2010). They can be rather superficial, having been espoused to make an impression on an audience (Fenton \& Inglis, 2007). As such, organisations' articulated values will often be contradicted by the behaviour of the employees (Chong, 2007). To serve as 'real guidance systems', values should firstly be internalised by everyone in the organisation, and secondly be 'reviewed at intervals to maintain relevance in changing contexts', both of which rarely happen (Serrat, 2010, p. 2).

The saying 'walk the talk' captures the challenges many organisations face if they are to enact their espoused values (Fenton \& Inglis, 2007). Value enactment is in many ways an alignment between the words (espoused values) of an organisation and its deeds (Dym \& Hutson, 2005). This alignment of words and deeds is central to value implementation (Fenton \& Inglis, 2007; Travaglione et al., 2009). If values are to be successfully integrated in an organisation, espoused and enacted values must be aligned. Espoused values are often no more than a list of values 
provided by the senior management of an organisation; value enactment, on the other hand, is central to value implementation and requires a deeper level of interpretation and internalisation within the organisation (Fenton \& Inglis, 2007; McGaw \& Fabish, 2006). Therefore, proper value internalisation within all levels of an organisation is imperative for value enactment. The current study specifically explores the extent of value internalisation at different levels and within different units of an organisation. Before the value internalisation framework of this study can be explained, however, it should be contextualised within the value internalisation practices found in the literature.

\section{Literature review}

\section{Different approaches to value internalisation}

Finding meaningful ways to institutionalise values is a challenge for any organisation that is attempting to put its core values into practice (Gruys et al., 2008). Although most of the research on organisational values and corporate values focuses on the benefits organisations may reap by being values-driven, little research has been dedicated to explaining the processes of value internalisation (Morginson, 2009). Those processes that have been found in the literature will be discussed here, as well as some of the important aspects of those processes, such as the roles of management and socialisation (both of which are prominent in the literature).

Sullivan et al. (2002) discuss the process of becoming a valuesled organisation and identify three phases in the process, (1) identifying the organisational values, (2) building ownership of these values within the organisation and (3) aligning the espoused and enacted values. The first phase involves only a small part of the organisation, that is, management teams and sometimes representatives from lower level employee groups. Begley and Boyd (2000) refer to the use of focus groups of employees. These small subsets of the organisation choose the organisational values. After the values have been identified, it is important that they be tested with a wider group of people within the organisation. This is also the beginning of the second phase of the process which is the process of building ownership of the values within the whole organisation.

To build ownership of the values employees need to be given a chance to establish the overlap of their own values with those of the organisation. Sullivan et al. (2002) stated:

This overlap is important because it enables the individual to behave in ways that are meaningful to them personally and the results in their connecting with, and become committed to, the organisation - while at the same time furthering the company's aims (p. 250).

The overlap of personal and organisational values is referred to as value congruence. It is not sufficient that employees know the organisational values; they should also believe in and internalise them (Chong, 2007).

Value congruence and more specifically its benefits have been documented extensively in the literature. These benefits include a positive work attitude (Posner, 2010), increased job satisfaction (Edwards \& Cable, 2009; Posner, 2010; Verquer, Behr \& Wagner, 2003), increased organisational commitment (Posner, 2010; Liedtka, 1989), increased organisational trust, intrinsic motivation, higher levels of organisational performance (Posner, 2010; Ren, 2010) and an increase in the extent to which the employee feels connected to the organisation and its values (Bartlet \& Ghoshal, 1994; Valentine, Godkin \& Lucero, 2002). Chong (2007) described the way in which organisational congruence gives external stakeholders an experience of the values, which, in turn, leads to an organisation attaining a sustainable competitive advantage.

Socialisation is the most important method of achieving value congruence as it is the primary method of transmitting and maintaining shared values (Cable \& Parsons, 2001; Cazier, Shao \& Louis, 2007; Grojean et al., 2004). Socialisation ensures that there is continuity in values as it provides employees with a framework of appropriate behaviours in various situations in their work environment (Cable \& Parsons, 2001). A single socialisation event is, however, not sufficient; successful value transmitting requires a number of different socialisation events over time, such as during entry into the organisation, all training and development opportunities as well as regular internal communication opportunities, such as internal company newsletters or magazines (Chong, 2007).

Cable and Parsons (2001) argue that specific socialisation tactics increase congruence between employee values and organisational values. Sequential and fixed socialisation tactics by which newcomers are oriented with regard to their career progression and the sequence of activities they have to go through in their work situation are successful in producing change in personal value systems. In terms of the social aspects of socialisation, serial and investiture socialisation tactics as opposed to disjunctive and divestiture tactics are more successful in producing change in personal value systems. Disjunctive tactics are those that 'force newcomers to develop their own definitions of situations' (Cable \& Parsons, 2001, p. 7) without the help of experienced members of the organisation. Divestiture socialisation tactics result in newcomers receiving negative social communication from insiders until they begin to fulfil the expectations implied by the organisation's values. If serial and investiture socialisation occurs, those who are new to the value systems receive positive social support from and spend time with members who know and have adopted the values. This type of socialisation is common in coaching and mentoring programmes. Highly institutionalised socialisation tactics which are systematic and planned by the organisation with the aim or reducing ambiguity in employees are more successful in changing employee values and creating congruence between employee and organisational values (Kim, Cable \& Kim, 2004).

Van Maanen and Schein (1979) discussed institutionalised role orientation socialisation tactics and individualised role orientation tactics. The former entails teaching individuals 
to respond in the same way that existing members in the organisation do. This approach relies heavily on obedience and conformity to existing practices. The latter tactic allows individuals to exercise their own creativity and innovation, and to experiment with changing norms and values. The application of these tactics will depend on the organisational context.

The socialisation programmes mentioned by Sullivan et al. (2002) include making the employees aware of their own and the organisation's values through a process of discussion, workshops and organisational coaching. Employees are given the opportunity to engage with the 'new' organisational values so that they may develop an understanding of them. Engagement processes must involve activities through which a shared understanding of expected work behaviours is established. Activities should be aimed at the intellectual as well as emotional involvement of those present (Sullivan et al., 2002). Begley and Boyd (2000) mention that activities during training or socialisation programmes should not only improve awareness levels but also improve the application of the values. They suggest the use of decision-making exercises in which the values are applied in concrete situations. Chong (2007) stresses that communication should be participative in nature and mentions, as an example, discussions which engage participants.

Aggerholm, Anderson, Asmuß and Thomsen (2009) also focus on organisational socialisation. They emphasise the importance of management communication in the process of value internalisation. For them, management communication is not only a tool for control and information dissemination, but also for the achievement of employee cooperation and for aligning employees values with organisational values. Management communication should articulate and actively communicate the company's values by means of internal communication methods and various types of management conversations. Communication does not, however, necessarily lead to enactment. 'For corporate values to be more than just words, the values portrayed must be integrated in various symbols and in the daily procedures of the organisation' (Aggerholm et al., 2009, p. 266). For instance, management speeches, reward systems, rituals and ceremonies should all be imbedded in the organisational values. Aggerholm et al. (2009) focus specifically on management conversations as a strategy for value integration. Management conversations include conversations such as recruitment conversations, job appraisal interviews, sickness leave conversations and dismissal conversations. It is clear from this list that organisational values need to be deeply integrated in management behaviour if they are to be integrated into organisational conversations at this level.

In the last phase of the process of becoming a valuesled organisation, as described by Sullivan et al. (2002), espoused values should be aligned to the behaviour of the individual employees as well as that of the organisation as a whole. In the case of the former, value enactment should always be visible in the behaviour of the management team. Many researchers have considered the importance of management in the creation of an organisation's value system (Grojean et al., 2004). Sullivan et al. (2002, p. 228) hold that 'it is crucial that the management be seen to be living the values and actively working on dealing with shortfalls in their own behaviour'. In addition Grojean et al. (2004, p. 228) mention that 'the behaviour of leaders is a powerful communication mechanism that conveys the expectations, values and assumptions of the culture and climate to the rest of the organization'. The behaviour of direct leaders is one of the primary influences on individual employee behaviour (Grojean et al., 2004).

Grojean et al. (2004) discuss various mechanisms by which leaders can transmit organisational values. These include values-based leadership, especially transformation and charismatic approaches; modelling behaviour that are congruent with organisational values; establishing clear expectations through appropriate policies, practices and training and formal socialisation activities; providing feedback on employee behaviour through coaching and mentoring employees; recognising and rewarding value supportive behaviour by employees through both formal and informal measures. The congruence between managers' and subordinates' values may be a mediating factor in individual organisational values congruence since the interpersonal congruence between supervisor and subordinates is related to the quality of leader-member exchange (Grojean et al., 2004). Leaders throughout the organisation should also send consistent messages with regard to their value orientation. This implies a shared cognisance of the organisational values. Leader training in this regard, as well as in transmitting the values, may be advantageous to the process of value internalisation. Begley and Boyd (2000) suggest training for managers and supervisors in small group settings to educate them on the organisation's values.

In terms of the organisation as whole, the processes and systems within the organisation need to be consistent with its values. If there are forces within the organisation, such as different subsystems or departments, which do not share the organisational values, it may cause a negative organisational climate regarding its values. Communication, or rather articulation, of these values in a formal and systematic way to ensure an understanding of it throughout the organisation is essential. It is also the first step towards a value-driven organisation (Begley \& Boyd, 2000). According to Morginson (2009) any management control system such as e-mail can be used to send regular messages with regard to the values and their meaning within the organisation. Other mechanisms that are used to communicate core values include the drafting of credos, mission statements, statements of purpose, policy manuals and similar documents, all of which convey the core values to the organisation by formalising them, making them more visible and reinforcing them. Mechanisms which rely on indirect communication may not be taken seriously (Morginson, 2009); on the other hand, if values are not yet 
inculcated, articulation may leave latitude for more than one interpretation (Begley \& Boyd, 2000). A deep level of understanding of and engagement with the organisational values should not be forgotten in the internalisation efforts (Simmons, 2002). Begley and Boyd (2000, p. 11) suggest that when values are articulated there should be a guideline statement for each value which applies the value to specific work domains and will therefore help to instil them through 'patterns that are expected to characterise value-based decision-making'.

The internalisation process as described and discussed by Sullivan et al. (2002) is not a once-off process; regular reinforcement and renewal should be implemented to assure that the values stay alive in the minds of the employees. In a case study of Singapore Airlines, Chong (2007) describes the process of communication of its core values as relentless; the company's core values are communicated when new employees first join, when employees attend training programmes and corporate events, and through internal communication channels such as company magazines and pocket-size copies of the core value statements. Furthermore an evaluation system is in place which ensures that employees' behaviour is consistent with the company's core values. Morginson (2009) refers to the 'Friday afternoon e-mail' from the chief executive officer (CEO); it contains his views on the progress of value implementation and usually includes reminders of the rationale behind the programme and clarification on its strategic importance.

The level of authority of the individuals who implement the internalisation of values is an important factor to consider. Serrat (2010) reports that in a study involving the senior management of 365 companies from 30 countries, $85 \%$ of the respondents believed that the CEO's support in reinforcing the values was critical, and $77 \%$ were of the opinion that the CEO's involvement was one of the most important value implementation practices.

The Value Inculcation Model (VIM) of Speculand and Chaudhary (2008) also provides some clarification on value internalisation. The authors describe four phases in the process of value internalisation, (1) identifying or renewing organisational values, (2) changing the attitude of the employees, (3) changing the behaviour of the employees and (4) changing the organisational performance. As did Sullivan et al. (2002), they stress the importance of the employees' understanding of the values but add that not only the desired behaviour, but also the desired attitude should be linked to the values. The key focus of their model is changing the employees' behaviour so that it is consistent with the organisational values. Their argument simply rests on the behavioural model which advocates that when employees display the desired behaviour they should be encouraged to repeat the behaviour until it becomes a deeply ingrained habit. Encouragement, according to Speculand and Chaudhary (2008), rests on leaders' implementing measures to track performance and to provide feedback on and recognition of acceptable behaviour.
Whilst there is similarity between the VIM and the process described by Sullivan et al. (2002), Hyde and Williamson (2000) describe a different approach. They advocate that instead of a small subset of the organisation identifying organisational values and then 'selling' them to the rest of the organisation, values should be selected by identifying and describing the values of the employees. Identifying values should incorporate a 'rich process of discussion and debate' (p. 12), after which the process of alignment can start. The latter includes an effective selection process to attract and recruit the right staff, value induction and training programmes, providing incentives and rewards for desired behaviour, and imposing penalties and sanctions for nondesired behaviour. Posner et al. (1985, p. 305) reflect on similar value related practices, such as programmes to clarify and communicate values, recruitment selection and orientation, training, rewards systems and counselling support to create a value advantage. As did Sullivan et al. (2002), Hyde and Williamson (2000) emphasise ownership of the values by the employees. They agree with VIM in that they believe employees should be held accountable for reaching tangible outcomes based on clear performance targets.

None of the literature discussed above is specifically dedicated to evaluating internalisation within public service organisations, which is the sector on which the current study focussed. Although their approach has not been described in an academic publication, the United States Air Force (1997) claims that its value implementation practices entail sound horizontal and vertical integration within the organisation, that their approach contributes to a deep level of interpretation and internalisation of value enactment within the organisation, and that it has a top-down, bottomup and back-and-forth approach. In the top-down approach the leaders make a sincere statement of personal commitment to their core values, educate and train staff with regard to the values at all levels within the organisation, engage immediate subordinates in discussions on the specific roles the values play in the organisation, and consciously include the core values in all feedback and mentoring sessions to subordinates, with special emphasis on operational application. The bottom-up approach includes all the members within the organisation. They have to examine all policies, processes and procedures that may contribute to a culture of compromise. This includes listing circumstances in which members of the organisation are tempted to act in a manner inconsistent with their core values, sharing their feelings with others in the organisation to identify common patterns of potential compromise, and finally identifying possible causes of these recurrent patterns. The back-and-forth approach includes active engagement of all the members of the organisation in wide ranging discussions to find the best ways to internalise the organisation's core values. This approach is more focussed on the articulation of values and establishing ownership (as described in the process of Sullivan et al. [2002]) than on aligning espoused and enacted values (Sullivan et al., 2002) or changing employee behaviour (VIM). 


\section{Research objectives}

The aim of this article is two-fold: firstly to offer a description of the value internalisation efforts that were used in a public service organisation in South Africa and secondly to report on the findings of an evaluation of the extent to which value internalisation efforts within a specific public service organisation actually led to value internalisation at all levels within the organisation. In the following section the value internalisation framework as well as the efforts that this organisation implemented will be described. Since the description of the efforts of the organisation is not part of the empirical study, it will precede the methodology of the evaluation.

\section{The value internalisation framework of this study}

The organisation embarked on a journey to establish an organisational culture of excellence in support of its core business. A new value system was developed to effect organisational change. As this particular organisation is in the safety and security industry (which includes organisations such as the SAPS, SANDF, private security providers and emergency personnel such as paramedics), transformation from a rule-bound culture, characterised predominantly by rigidity, tight procedural and regulatory control and considerable resistance, to a value-driven culture with a strong sense of enthusiasm and commitment, based on the inherent talent, creativity and competence of its people, was necessary (Beukman, 2005, p. 159). Little is known about how value systems are used to engineer organisational change or how value systems are implemented to this effect (Morginson, 2009).

To support a culture of excellence, the organisation introduced a newly developed principle-centred value system, promoted as the slogan: 'Integrity, human dignity and excellence in all we do.' This slogan was to act as the primary vehicle to facilitate the required culture changes. Covey (2003) emphasises the importance of aligning values with universal principles to bring about more parity in people's actions and behaviours. The values that were developed and used by this particular organisation are, of course, not unique to the organisation. They are universal and used by many organisations. Integrity, for instance, is one of the most commonly found organisational values (Sullivan et al., 2002). It is a core organisational value of the United States Air Force (1997), the Springfield city council (http:/ / www.ci.springfield.or.us) and the United States National Park Service (Serrat, 2010), to name but a few.

Human dignity is also a core organisation value of many organisations, including, for example, the Oil Turbo Compressor Group (http:/ / oilturbocompressor.com) and the Seniors Home Care group (http://www.seniorshomecare. com/). Similarly, Excellence in all we do was formally adopted as a core value by the United States Air Force (1997) and the Leadership Development Network (http://www. leadershipdevelopmentnetwork.com) also sees it as one of their core leadership principles. Similar values are found in a review of the most prominent organisational values of public sector organisations (Van der Wal \& Huberts, 2008). There are a number of organisations who use similar combinations of values (e.g. Microsoft, Johnson \& Johnson and Hewlett Packard).

The organisation under discussion chose its core values after the core values of many other organisations had been studied. Focus groups, strategic work sessions and brainstorming sessions with senior management were held over a six-month period before the choice of values was finalised.

For this organisation, integrity was defined in the most practical terms. It is based on the principle of doing what is right even when nobody is watching over you. Integrity is also the cornerstone of trust, an element of leadership that is fundamental for successful relationships. Integrity provides the basis for establishing leadership credibility within the organisation. Human dignity is based on the principle of treating others the way you would be treated. The behaviours associated with this value reflect how leaders create the conditions in the workplace for their followers to do what needs to be done and to develop them to the highest level of their own potential. These behaviours not only refer to the relationship between leaders and followers, but also indicate how members should interact with one another within the organisation. Excellence in all we do refers to the value of being an organisation of excellence. It is directly linked to continuous improvement. If a mindset of continuous improvement is to be created, people's creative potential must be utilised to enable them to 'do more with less'. In embracing excellence people within the organisation must be allowed to unleash their full innovative powers and potential through an achievement and performance culture.

In order to facilitate the internalisation of these values, an extensive implementation framework consisting of various actions and endeavours by different role players within the organisation was introduced. The actions and endeavours included:

- The organisation's values were set out and explained in a clear belief statement, and this was accompanied by a list of behaviours highlighting the nature and intent of the values. This was aimed at enhancing the understanding and practical application of value-driven practices within the organisation.

- The three chosen values were conceptualised and illustrated through references to the behavioural patterns of eagles. Branded value material in the form of posters, key rings, CDs and DVDs was distributed throughout the organisation. The aim of this initiative was to achieve a cognitive and, above all, an emotional connection with the new values so as to bring about higher levels of association with and commitment to the new required behaviour within the organisation.

- The senior executive conducted a road show to communicate the importance of these values within the 
organisation. This was intended to demonstrate a unified, top-down approach to what was expected within the organisation.

- All key role players were issued with a framework to aid in the institutionalisation of the values based on a process of socialisation, integration and recognition. This framework was aimed at facilitating the incorporation of the values into existing practices, policies and procedures. This practice was seen as critically important to change behaviour throughout the organisation and was intended to promote horizontal and vertical dialogue on the relevance of value related practices and behaviours.

- Extensive training interventions took place to aid the understanding and internalisation of the values. Approximately 3000 employees were exposed to these interventions. The aim of the training sessions was to create awareness of the new value behaviours required. They were also aimed at facilitating a changed mindset in terms of achieving better congruence and acceptance of the values. Those leaders in the organisation who had the greatest responsibility in modelling and shaping the new values of the organisation were required to attend the training.

Despite the intense nature of the value internalisation efforts, there was no guarantee that they actually led to changed values in the organisation. The remainder of this article describes the methodology used to evaluate the extent to which internalisation did take place as well as the results of the study.

\section{Research design Research approach}

A non-experimental quantitative design was appropriate because of the descriptive nature of the study. A questionnaire was developed to measure the extent of value internalisation at the different levels and in the various units of the public service organisation. Respondents completed the questionnaire three months after the conclusion of the internalisation efforts.

\section{Research method}

\section{Research participants}

Non-probability quota sampling of a cross-section of the population was carried out, taking into account demographically and organisationally distinguishing factors. The sample size was determined by obtaining a quota from each unit of the organisation (Table 1). With the initial sample design a $10 \%$ sample from each of the 14 units within the entire organisation was planned. This $10 \%$ sample size of each unit was also planned to be representative of the respective unit size, compared to the total size of the organisation (11 060 employees). Of the 14 units from which samples were obtained, six achieved a sample representation of $10 \%$ and higher, three a sample size of between $6 \%$ and $9 \%$ and five a sample size of less than $5 \%$.

In terms of the overall unit of analysis, categories were identified to obtain a suitable sample representation of
TABLE 1: Unit representation.

\begin{tabular}{llll}
\hline Number & Unit & Sample size & Percentage \\
\hline 1 & Main unit 1 & 203 & 23.41 \\
2 & Main unit 2 & 122 & 14.07 \\
3 & Main unit 3 & 28 & 3.23 \\
4 & Advance training unit & 16 & 1.85 \\
5 & Operational training unit & 89 & 10.27 \\
6 & Main unit 4 & 68 & 7.84 \\
7 & Operational test centre & 32 & 3.69 \\
8 & Basic training unit & 20 & 2.31 \\
9 & Main unit 5 & 115 & 13.26 \\
10 & Main unit 6 & 24 & 2.77 \\
11 & Technical training unit & 24 & 2.77 \\
12 & Headquarters & 42 & 4.84 \\
13 & Main unit 7 & 12 & 1.38 \\
14 & Mobile deployment unit & 72 & 8.30 \\
\hline
\end{tabular}

TABLE 2: Management level representation.

\begin{tabular}{llll}
\hline Number & Level & Frequency & Percentage \\
\hline 1 & Non-management & 500 & 53.13 \\
2 & Supervisory level & 291 & 30.92 \\
3 & Middle management level & 95 & 10.10 \\
4 & Higher management level & 49 & 5.21 \\
5 & Top management level & 6 & 0.64 \\
\hline Total & - & $\mathbf{9 4 1}$ & $\mathbf{1 0 0}$ \\
\hline
\end{tabular}

employees' gender, race, age, managerial level and experience levels. Questionnaires were sent to 1060 employees (out of the total population 11060 employees). A 89\% response rate was achieved (941 questionnaires were returned and were usable for analysis), although the response rate differs per question on the survey if the missing values are taken into account ${ }^{1}$.

Of the respondents who completed the survey, $83.28 \%$ represented the non-managerial to middle management levels of the organisation (Table 2). In terms of age the largest group represented was the age group between 25 and 44 (Table 3). Seventy-seven percent of the sample was male and $23 \%$ female, which replicates the gender distribution in this specific organisation. Of the respondents, $36.78 \%$ had 11 or more years' experience and $54.21 \%$ had ten years' or less experience in the organisation (Table 4). In terms of race representation, the sample consisted of 25 Asian (2.88\%), 363 White (41.87\%), 138 Mixed race (15.92\%) and 341 Black $(39.33 \%)$ respondents (Table 5).

Of the above mentioned categories a suitable sample representation of certain units, gender, race, age, and experience levels was obtained in terms of the total unit of analysis, with the exception of managerial levels, where lower managerial levels had a significantly higher representation than senior management levels and there were some units with a smaller than $10 \%$ sample. The sample obtained served the purpose of a non-probability quota design, namely to obtain a replica of the population, one that represented the population as such as closely as possible.

1.If missing values are taken into account, the lowest response rate is $79 \%(N=865)$. 
TABLE 3: Age distribution of participants.

\begin{tabular}{llll}
\hline Number & Age groups & Frequency & Percentage \\
\hline 1 & $\leq 19$ & 10 & 1.15 \\
2 & $20-24$ & 137 & 15.80 \\
3 & $25-34$ & 415 & 47.87 \\
4 & $35-44$ & 222 & 25.61 \\
5 & $45-54$ & 73 & 8.42 \\
6 & $55-64$ & 9 & 1.04 \\
7 & $65 \leq$ & 1 & 0.12 \\
\hline Total & - & 867 & 100 \\
\hline
\end{tabular}

TABLE 4: Years experience within the organisation.

\begin{tabular}{llll}
\hline Number & Years experience & Frequency & Percentage \\
\hline 1 & $0-5$ & 202 & 23.30 \\
2 & $6-10$ & 268 & 30.91 \\
3 & $11-15$ & 188 & 21.68 \\
4 & $16-20$ & 109 & 12.57 \\
5 & $21-30$ & 81 & 9.34 \\
6 & $30+$ & 19 & 2.19 \\
\hline Total & - & 867 & 100
\end{tabular}

TABLE 5: Racial (population) distribution.

\begin{tabular}{llll}
\hline Number & Level & Frequency & Percentage \\
\hline 1 & Asian & 25 & 2.88 \\
2 & White & 363 & 41.87 \\
3 & African & 341 & 39.33 \\
4 & Mixed race & 138 & 15.92 \\
\hline Total & - & $\mathbf{8 6 7}$ & $\mathbf{1 0 0}$ \\
\hline
\end{tabular}

TABLE 6: Eigenvalue classification.

\begin{tabular}{ll}
\hline Factor (component) & Eigenvalue \\
\hline 1 & 11.13 \\
2 & 2.85 \\
3 & 1.13 \\
4 & 0.97 \\
5 & 0.95 \\
6 & 0.89 \\
\hline
\end{tabular}

\section{Measuring instrument}

A value inventory (VI) consisting of 43 items was developed specifically to measure whether values had been internalised by the employees. A tailor-made questionnaire was necessary, since existing questionnaires do not measure the underlying values of the organisation and cannot therefore contribute to the process of establishing whether real value internalisation had taken place, which was the aim of the study.

Items were measured on a 5-point rating scale: 1 (always), 2 (most of the time), 3 (sometimes), 4 (almost never), 5 (never). In the original questionnaire a sixth option, 'Don't know', was included, but as processing the data both with and without the sixth option yielded no significant difference, the sixth option was excluded.

A factor analysis was conducted in order to obtain adequate representation of the relevant values. Data were subjected to item and factor analysis. Since only factor loadings of above 0.3 were considered, 12 items were omitted (Kline, 1997, p. 5). The Kaiser criterion for factor extraction was used and six factors were identified (Table 6). Since the Kaiser criterion is widely criticised (Velicer \& Jackson, 1990), a Scree plot was also applied (Costello \& Osborne, 2005). The Scree plot results retained three factors (Table 7 ).

A Quartimin (oblique) factor rotation was used to determine a clear pattern of loadings of the factors (Table 8). Quartimin rotation attempts to maximize the spread of factor loadings for a variable across all factors (Field, 2009).

The results of a factor analysis represented three distinct value components, namely 'leadership credibility', 'people first' and 'achievement orientation', each being relevant to the defined values of the public service organisation. The first factor, leadership credibility, did not measure leadership integrity directly, but it was an important consideration in the value of leadership integrity. Leadership integrity from this perspective can be established only if the leader is seen as credible by his or her followers. Leadership credibility is that part of the leader's character that determines his or her integrity. Without credibility there is no leadership integrity.

The second factor related to the importance of putting people first and underpinned the value of human dignity. Putting people first reflected the way in which leaders created conditions in the workplace to maximise their followers' potential. By putting people first, the organisation upholds people's dignity by respecting them and valuing their human ability and competence.

The third factor reflected the importance of creating a mindset of achievement orientation, thereby supporting the establishment of excellence. Excellence can be achieved only if a mindset of achievement is established. This mindset is created if people in the organisation are rewarded and recognised for their efforts and achievements.

The questionnaire's reliability was determined by using Cronbach's alpha coefficient. According to Hinton, Brownlow, McMurray and Cozens (2004, p. 357) 0.75 reliability is a sensible comprised value to determine reliability. According to the reliability indicators all three factors as well as the overall alpha were above 0.80 (Table 9).

\section{Research procedure}

Permission to conduct the study was obtained from the public service organisation. Three months after the internalisation efforts were rolled out and implemented, organisational culture workshops were conducted at the various units of the organisation. All of employees in the units that were on strength on the day of the workshop attended it. After the workshops the delegates were invited to take part in the study by completing the questionnaire.

Delegates that volunteered to take part in the study were briefed on the aim of the study, the confidentiality of their responses, voluntary participation and instructions for completing the questionnaire. The respondents had the right 
TABLE 7: Scree plot.

\begin{tabular}{|c|c|c|}
\hline \multicolumn{2}{|c|}{ Eigenvalue } & \multirow{2}{*}{ 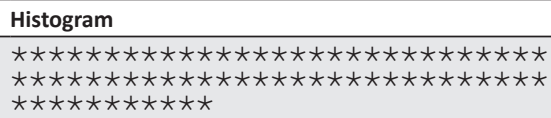 } \\
\hline 1 & 11.1306 & \\
\hline 2 & 2.85454 & 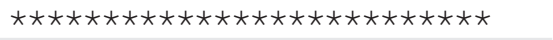 \\
\hline 3 & 1.12572 & 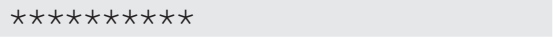 \\
\hline 4 & 0.973326 & 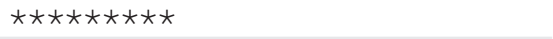 \\
\hline 5 & 0.951495 & 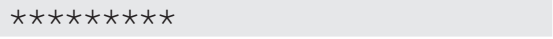 \\
\hline 6 & 0.887678 & 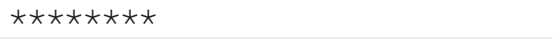 \\
\hline 7 & 0.826942 & 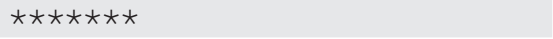 \\
\hline 8 & 0.821137 & 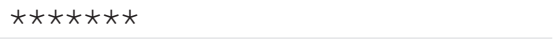 \\
\hline 9 & 0.754494 & 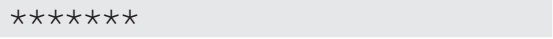 \\
\hline 10 & 0.730450 & 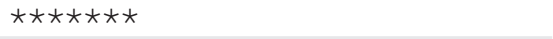 \\
\hline 11 & 0.698655 & 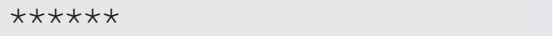 \\
\hline 12 & 0.668504 & 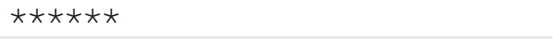 \\
\hline 13 & 0.638364 & 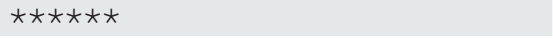 \\
\hline 14 & 0.599569 & $\star \star \star \star \star ~$ \\
\hline 15 & 0.582022 & 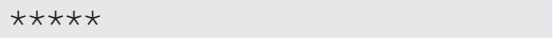 \\
\hline 16 & 0.553773 & 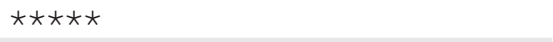 \\
\hline 17 & 0.528902 & 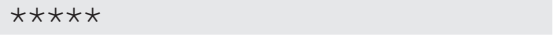 \\
\hline 18 & 0.510998 & 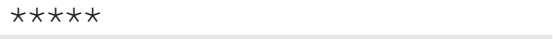 \\
\hline 19 & 0.497973 & 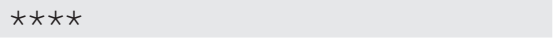 \\
\hline 20 & 0.468488 & 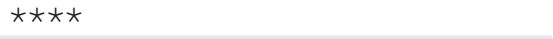 \\
\hline 21 & 0.457805 & 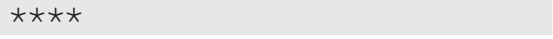 \\
\hline 22 & 0.434161 & 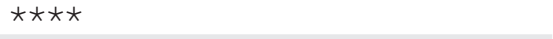 \\
\hline 23 & 0.416694 & 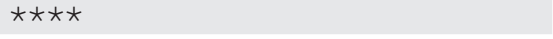 \\
\hline 24 & 0.411475 & 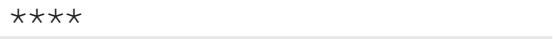 \\
\hline 25 & 0.394946 & $\star \star \star \star ~$ \\
\hline 26 & 0.389706 & 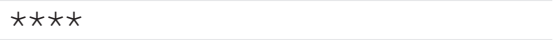 \\
\hline 27 & 0.371167 & 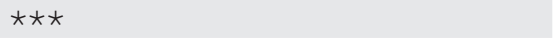 \\
\hline 28 & 0.344497 & 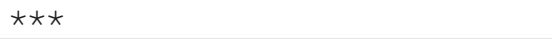 \\
\hline 29 & 0.339170 & 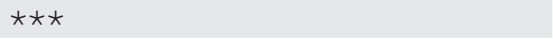 \\
\hline 30 & 0.326320 & 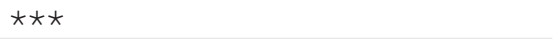 \\
\hline 31 & 0.310468 & $\star \star \star$ \\
\hline
\end{tabular}

to withdraw from the study at any stage. They did not provide their names or personnel numbers on the questionnaires. Consent was assumed when the respondents completed the questionnaires. In total 932 questionnaires were completed by means of this process.

\section{Statistical analysis}

Descriptive statistics were used to measure the degree of value internalisation. Analysis of variance (ANOVA) was employed to assess differences in internalisation between demographical groupings and units. This was important for determining the extent of internalisation throughout the organisation.

\section{Results \\ Descriptive statistics}

The overall mean scores for each value component (leader credibility, people first and achievement orientation) indicated average mean scores in comparison to the scale values used. Value components 2 and 3 (people first and achievement orientation) had the highest mean scores, 2.82 and 2.89 respectively, and were the closest to the scale value 3 of the survey. At 2.67, leader credibility had the lowest mean score. Higher scores indicate higher levels of internalisation and lower scores lower levels of internalisation.
TABLE 8: Quartimin factor rotation.

\begin{tabular}{|c|c|c|c|}
\hline Item number (question) & Factor 1 & Factor 2 & Factor 3 \\
\hline Q5 & 0.755 & 0.000 & 0.000 \\
\hline Q6 & 0.728 & 0.000 & 0.000 \\
\hline Q10 & 0.715 & 0.000 & 0.000 \\
\hline Q7 & 0.703 & 0.000 & 0.000 \\
\hline Q13 & 0.690 & 0.000 & 0.000 \\
\hline Q8 & 0.649 & 0.000 & 0.000 \\
\hline Q11 & 0.630 & 0.000 & 0.000 \\
\hline Q1 & 0.629 & 0.000 & 0.000 \\
\hline Q4 & 0.623 & 0.000 & 0.000 \\
\hline Q14 & 0.594 & 0.000 & 0.000 \\
\hline Q15 & 0.587 & 0.000 & 0.000 \\
\hline Q9 & 0.517 & 0.000 & 0.000 \\
\hline Q34 & 0.000 & 0.715 & 0.000 \\
\hline Q35 & 0.000 & 0.687 & 0.000 \\
\hline Q31 & 0.000 & 0.685 & 0.000 \\
\hline Q29 & 0.000 & 0.673 & 0.000 \\
\hline Q37 & 0.000 & 0.608 & 0.000 \\
\hline Q39 & 0.000 & 0.604 & 0.000 \\
\hline Q32 & 0.000 & 0.549 & 0.000 \\
\hline Q16 & 0.000 & 0.531 & 0.000 \\
\hline Q30 & 0.000 & 0.525 & 0.000 \\
\hline Q36 & 0.000 & 0.501 & 0.000 \\
\hline Q25 & 0.000 & 0.000 & 0.786 \\
\hline Q26 & 0.000 & 0.000 & 0.712 \\
\hline Q23 & 0.000 & 0.000 & 0.561 \\
\hline Q24 & 0.000 & 0.000 & 0.466 \\
\hline Q19 & 0.000 & 0.443 & 0.000 \\
\hline Q38 & 0.000 & 0.485 & 0.000 \\
\hline Q3 & 0.374 & 0.000 & 0.000 \\
\hline Q33 & 0.000 & 0.356 & 0.000 \\
\hline Q43 & 0.000 & 0.429 & 0.000 \\
\hline Total variance & 5.384 & 4.689 & 1.815 \\
\hline
\end{tabular}

TABLE 9: Questionnaire reliability.

\begin{tabular}{ll}
\hline Factor & Alpha \\
\hline Leader credibility (Factor 1) & 0.906 \\
People first (Factor 2) & 0.896 \\
Achievement orientation (Factor 3) & 0.829 \\
Overall reliability & 0.939 \\
\hline
\end{tabular}

The results per unit, gender, race, managerial level, age group and experience levels can be seen in Table 10 - Table 15 .

\section{Comparisons}

Analysis of variance was used to determine whether there were any significant differences within the various independent variables, namely unit, age, population, gender, managerial levels and work experience based on each identified factor (dependent variable). $\operatorname{Pr}>F$-values smaller than 0.05 were used to determine whether there were significant differences within groupings.

The results based on the ANOVAs indicated that there were significant differences within only two independent variables of the identified value components, namely population (race) and unit (Tables 16, Table 17 and Table 18). However, the significant difference for population (race) between Black $(39.33 \%)$ and White staff $(41.87 \%)$ was reflected only for factor 1 , leader credibility $\left(\mathrm{M}_{\text {White }}=2.504 ; \mathrm{SD}_{\text {White }}=2.907\right.$; $\left.\mathrm{M}_{\text {Black }}=2.907 ; \mathrm{SD}_{\text {Black }}=0.767\right)$. 
TABLE 10: Descriptive statistics for organisational units.

\begin{tabular}{|c|c|c|c|c|c|c|}
\hline \multirow[t]{2}{*}{ Organisational unit } & \multicolumn{2}{|c|}{ Factor 1} & \multicolumn{2}{|c|}{ Factor 2} & \multicolumn{2}{|c|}{ Factor 3} \\
\hline & Mean & SD & Mean & SD & Mean & SD \\
\hline Main unit 1 & 2.818 & 0.776 & 2.929 & 0.652 & 3.048 & 0.9157 \\
\hline Main unit 2 & 2.712 & 0.883 & 2.923 & 0.760 & 2.906 & 0.963 \\
\hline Main unit 3 & 2.690 & 0.856 & 2.740 & 0.825 & 2.759 & 0.963 \\
\hline Advance training unit & 2.120 & 0.595 & 2.402 & 0.653 & 2.375 & 0.996 \\
\hline Operational training unit & 2.386 & 0.705 & 2.699 & 0.579 & 2.801 & 0.750 \\
\hline Main unit 4 & 2.910 & 0.848 & 3.057 & 0.769 & 3.235 & 0.918 \\
\hline Basic training unit & 2.669 & 0.660 & 2.475 & 0.630 & 2.450 & 0.868 \\
\hline Main unit 5 & 2.5290 & 0.729 & 2.720 & 0.728 & 2.630 & 0.900 \\
\hline Main unit 6 & 2.391 & 0.704 & 2.554 & 0.712 & 2.531 & 0.956 \\
\hline Technical training unit & 2.609 & 0.725 & 2.726 & 0.584 & 2.656 & 0.929 \\
\hline Headquarters & 2.5623 & 0.829 & 2.862 & 0.657 & 3.179 & 0.918 \\
\hline Main unit 7 & 2.647 & 0.634 & 2.982 & 0.498 & 3.229 & 0.750 \\
\hline Mobile deployment unit & 3.062 & 0.775 & 3.039 & 0.778 & 3.222 & 0.985 \\
\hline
\end{tabular}

SD, standard deviation.

TABLE 11: Descriptive statistics for gender groupings.

\begin{tabular}{|c|c|c|c|c|c|c|}
\hline \multirow[t]{2}{*}{ Gender } & \multicolumn{2}{|c|}{ Factor 1} & \multicolumn{2}{|c|}{ Factor 2} & \multicolumn{2}{|c|}{ Factor 3} \\
\hline & Mean & SD & Mean & SD & Mean & SD \\
\hline Male & 2.599 & 0.794 & 2.722 & 0.662 & 2.867 & 0.963 \\
\hline Female & 2.625 & 0.825 & 2.788 & 0.680 & 2.909 & 0.957 \\
\hline
\end{tabular}

SD, standard deviation.

TABLE 12: Descriptive statistics for race groupings.

\begin{tabular}{|c|c|c|c|c|c|c|}
\hline \multirow[t]{2}{*}{ Race } & \multicolumn{2}{|c|}{ Factor 1} & \multicolumn{2}{|c|}{ Factor 2} & \multicolumn{2}{|c|}{ Factor 3} \\
\hline & Mean & SD & Mean & SD & Mean & SD \\
\hline Asian & 2.683 & 0.914 & 2.816 & 0.749 & 2.926 & 1.170 \\
\hline Black & 2.907 & 0.767 & 2.800 & 0.733 & 2.899 & 1.047 \\
\hline Mixed race & 2.550 & 0.793 & 2.611 & 0.644 & 2.675 & 0.845 \\
\hline White & 2.504 & 0.783 & 2.723 & 0.599 & 2.932 & 0.047 \\
\hline
\end{tabular}

SD, standard deviation.

TABLE 13: Descriptive statistics for managerial levels.

\begin{tabular}{|c|c|c|c|c|c|c|}
\hline \multirow[t]{2}{*}{ Managerial levels } & \multicolumn{2}{|c|}{ Factor 1} & \multicolumn{2}{|c|}{ Factor 2} & \multicolumn{2}{|c|}{ Factor 3} \\
\hline & Mean & SD & Mean & SD & Mean & SD \\
\hline Top management & 2.846 & 0.544 & 3.370 & 0.784 & 3.500 & 0.894 \\
\hline Higher management & 2.308 & 0.792 & 2.704 & 0.708 & 2.859 & 0.969 \\
\hline Middle management & 2.50 & 0.714 & 2.652 & 0.553 & 2.731 & 0.8114 \\
\hline Supervisory & 2.534 & 0.774 & 2.702 & 0.589 & 2.810 & 0.918 \\
\hline Non-managerial level & 2.720 & 0.833 & 2.770 & 0.723 & 2.937 & 1.009 \\
\hline
\end{tabular}

SD, standard deviation.

TABLE 14: Descriptive statistics for age groupings.

\begin{tabular}{|c|c|c|c|c|c|c|}
\hline \multirow[t]{2}{*}{ Age groupings } & \multicolumn{2}{|c|}{ Factor 1} & \multicolumn{2}{|c|}{ Factor 2} & \multicolumn{2}{|c|}{ Factor 3} \\
\hline & Mean & SD & Mean & SD & Mean & SD \\
\hline$\leq 19$ & 2.800 & 0.416 & 2.754 & 0.694 & 2.925 & 1.054 \\
\hline $20-24$ & 2.543 & 0.753 & 2.622 & 0.639 & 2.801 & 0.917 \\
\hline $35-44$ & 2.660 & 0.814 & 2.723 & 0.709 & 2.856 & 0.067 \\
\hline $45-54$ & 2.445 & 0.702 & 2.610 & 0.607 & 2.599 & 0.903 \\
\hline $55-64$ & 2.404 & 0.697 & 2.741 & 0.714 & 3.194 & 1.066 \\
\hline
\end{tabular}

SD, standard deviation.

$\dagger$, Only one respondent in this category; mean is therefore constant and SD reflects 0.00 .

TABLE 15: Descriptive statistics for experience levels.

\begin{tabular}{|c|c|c|c|c|c|c|}
\hline \multirow[t]{2}{*}{ Years experience } & \multicolumn{2}{|c|}{ Factor 1} & \multicolumn{2}{|c|}{ Factor 2} & \multicolumn{2}{|c|}{ Factor 3} \\
\hline & Mean & SD & Mean & SD & Mean & SD \\
\hline $0-5$ & 2.626 & 0.819 & 2.719 & 0.692 & 2.872 & 1.00 \\
\hline $6-10$ & 2.657 & 0.804 & 2.797 & 0.632 & 2.954 & 0.935 \\
\hline $11-15$ & 2.683 & 0.794 & 2.734 & 0.693 & 2.810 & 0.926 \\
\hline $16-20$ & 2.470 & 0.859 & 2.733 & 0.718 & 2.910 & 1.00 \\
\hline $21-30$ & 2.536 & 0.712 & 2.635 & 0.578 & 2.741 & 0.929 \\
\hline $30+$ & 2.188 & 0.602 & 2.522 & 0.626 & 2.750 & 1.00 \\
\hline
\end{tabular}

SD, standard deviation. 
TABLE 16: Factor 1 (Leader credibility): Comparison.

\begin{tabular}{|c|c|c|c|c|c|}
\hline Groupings & $d f$ & Sum of Square & Mean Square & $F$-value & $P r>F$ \\
\hline Unit & 13 & 42.848 & 3.296 & 3.66 & $<.0001$ \\
\hline Gender & 1 & 0.218 & 0.218 & 0.24 & 0.6228 \\
\hline Age & 4 & 3.900 & 0.975 & 1.08 & 0.3632 \\
\hline Rank & 3 & 4.457 & 1.486 & 1.65 & 0.1760 \\
\hline Population & 3 & 21.078 & 7.026 & 7.81 & $<.0001$ \\
\hline Work experience & 5 & 4.753 & 0.951 & 1.06 & 0.3830 \\
\hline
\end{tabular}

$d f$, degrees of freedom, $P r$, probability; $F$, frequency.

TABLE 17: Factor 2 (People first): Comparison.

\begin{tabular}{|c|c|c|c|c|c|}
\hline Groupings & $d f$ & Sum of Square & Mean Square & $F$-value & $\operatorname{Pr}>F$ \\
\hline Unit & 13 & 47.957 & 3.689 & 3.91 & $<.0001$ \\
\hline Gender & 1 & 0.1516 & 0.152 & 0.16 & 0.6885 \\
\hline Age & 4 & 6.0804 & 1.520 & 1.61 & 0.1690 \\
\hline Rank & 3 & 3.7138 & 1.238 & 1.31 & 0.2688 \\
\hline Population & 3 & 1.5483 & 0.516 & 0.55 & 0.6499 \\
\hline Work experience & 5 & 1.1472 & 0.229 & 0.24 & 0.9431 \\
\hline
\end{tabular}

$d f$, degrees of freedom, $P r$, probability; $F$, frequency.

TABLE 18: Factor 3 (Achievement orientation): Comparison.

\begin{tabular}{|c|c|c|c|c|c|}
\hline Groupings & $d f$ & Sum of Square & Mean Square & $F$-value & $P r>F$ \\
\hline Unit & 13 & 52.750 & 4.058 & 4.38 & $<.0001$ \\
\hline Gender & 1 & 0.1456 & 0.146 & 0.16 & 0.6918 \\
\hline Age & 4 & 8.3195 & 2.080 & 2.25 & 0.0624 \\
\hline Rank & 3 & 5.2677 & 1.756 & 1.90 & 0.1287 \\
\hline Population & 3 & 1.3959 & 0.465 & 0.50 & 0.6807 \\
\hline Work experience & 5 & 2.9411 & 0.588 & 0.64 & 0.6729 \\
\hline
\end{tabular}

$d f$, degrees of freedom, $P r$, probability; $F$, frequency.

There were also significant differences between various units in the organisation for all three factors: leader credibility, people first and achievement orientation. The post hoc comparisons showed that three units differed significantly $(<.0001)$ from one another in terms of factor 1: the Mobile Deployment unit $(\mathrm{M}=3.062 ; \mathrm{SD}=0.775)$ differed significantly from the Advanced Training unit $(\mathrm{M}=2.120 ; \mathrm{SD}=0.595)$, the Operational Training unit $(\mathrm{M}=2.386 ; \mathrm{SD}=0.705)$ and the Operational Test Centre $(\mathrm{M}=2.276 ; \mathrm{SD}=0.736)$. In terms of Factor 2 , significant differences were evident between the Operational Test Centre $(M=2.353 ; S D=0.642)$ and the Main unit $1(M=2.929$; $\mathrm{SD}=0.652)$, Main unit $2(\mathrm{M}=2.923 ; \mathrm{SD}=0.760)$, the Advanced Training unit $(M=2.402 ; \mathrm{SD}=0.653)$, Main unit $4(\mathrm{M}=3.057$; $\mathrm{SD}=0.769)$ and the Mobile Deployment unit $(\mathrm{M}=3.039$; $\mathrm{SD}=0.778)$. The largest differences were between the Main Unit 4 and the Operational Test Centre. For Factor 3, significant differences were found between the Operational Test Centre and four other units (Main unit 1 [M=3.048; SD = 0.914], Main unit $4[\mathrm{M}=3.324$; $\mathrm{SD}=0.918]$, Headquarters $[\mathrm{M}=3.179$; $\mathrm{SD}=0.918]$ and the Mobile Deployment unit $[\mathrm{M}=3.222$; $\mathrm{SD}=0.985]$ ).

\section{Ethical considerations}

Permission was given by the organisation for this research to be conducted. There were no risks involved in participation in this study. Each respondent was given a brief on their participation in which the focus of the study, their voluntary participation as well as the confidentiality of the data was explained. Questionnaires were completed anonymously be voluntary participants. The completed questionnaires were collected by the researcher.

\section{Trustworthiness}

At the time of this study, one of the researchers was employed in the organisation and was part of the team that developed the new value system. This insider view ensures a detailed description of the value internalisation process. The questionnaire was tailor-made for this specific study and its validity and reliability for the population was established.

\section{Discussion}

The study set out to describe the value internalisation efforts of a public service organisation in South Africa and to assess whether and to what extent value internalisation did take place within the entire organisation and also, more specifically, at the different managerial, unit, gender, age and experience levels. This evaluation was based on the premise that extensive efforts to inculcate newly introduced values such as extensive training, leadership involvement, focussed communication, socialisation and integration tactics should, if applied diligently, contribute to a higher value awareness and changed state (emotional and cognitive).

Average and lower than expected results were found. The responses obtained with regard to all three value constructs and their tendency to lean more towards scale value 3 (sometimes) indicated that the desired value behaviours were not prominent enough within the organisation. Although 
other factors could have affected these results, it was anticipated that pertinent and focussed newly introduced value related interventions and practices, by their very nature, should have contributed more positively to the internalisation results. Because of these lower than expected levels of internalisation, it can therefore be concluded that value congruence had not been achieved. If a critical appraisal is made of the internalisation efforts, the following can be commented on, (1) the identification of the values, (2) communication of values and (3) reinforcement of the values.

\section{Identification of the values}

Although the values were theoretically sound and relevant to the organisation, they had been developed by a small subset of the organisation. Sullivan et al. (2002) and Hyde and Williams (2000) all highlight the importance of including a large part of the organisation in the value identification phase. In this study the task team who chose the values for the organisation represented senior and top management levels only. When this approach is taken, it is difficult to establish ownership of values; Hyde and Williams (2000) claim that it is then rather a case of selling the values to the employees than fostering ownership of them.

\section{Communication of values}

An effort was made not only to articulate the values, but also to link the values to behaviour. Although considerable efforts (such as the CEO's road show as well as handing out posters, key rings, CDs and DVDs) were made to disseminate the values and their intent as well as the effect they could have on the organisation, these efforts were a once-off process. More socialisation events over a longer period of time would conceivably have been more effective in firstly establishing ownership of the values and secondly in bringing about congruence between individual and organisational values. If successful integration is to take place, values need to be communicated repeatedly over time (Cable \& Parsons, 2001; Chong, 2007; Grojean et al., 2004; Sullivan et al., 2002). In this study, the internalisation efforts were stopped at some point, implying a once-off process. It did not really allow for employees discovering their own values, as was recommended by Sullivan et al. (2002). The importance of continuous and repeated efforts for successful values implementation is stressed in the literature. More engaging and participative efforts aimed at an emotional level of engagement would perhaps have been more successful (Begley \& Boyd, 2000; Chong, 2007; Sullivan et al., 2002). Value congruence is typically established through these kinds of activities and internalisation can then take place.

\section{Reinforcement of values}

Communicated values need to be reinforced (Chong, 2007; Morginson, 2009; Sullivan et al., 2002). Garvin and Roberto (2005) in their studies of successful turnarounds found that effective leaders explicitly and constantly reinforced organisational values, using actions to back up their words.
They state that the leader's role is to change behaviour, and not just to apply ways of thinking to bring about change. Actions include publicly criticising disruptive and divisive behaviour and reinforcing correct behaviour through recognition and appraisals. Although the public service organisation had various formal mechanisms in place to demonstrate such actions during parades, formal ceremonies and prestige events, the results suggest that very little action was taken to reinforce and enact these new values continuously. Possibly this approach neglected the VIM premise that behaviour change was not necessarily closely associated with the attitude change required.

Significant differences in terms of dependent variables such as population groups and units within the organisation provided more evidence of a fragmented internalisation. The significant differences between the responses of Black and White staff on the leader credibility scale imply that leadership credibility is perceived differently by the two groups. This difference confirms that leadership credibility can be affected not only by managerial fashions and organisational change, as stated by Simons (2002), but possibly also by racial differences. Hofstede (1984, 1994, 1997, 2001) indicated that cultural differences as well as individual expectations and assumptions about leadership influence leadership behaviour. In a South African context, studies by Booysen (2001) and Littrell and Nkomo (2005) indicated that there were differences between Black and White leaders regarding preferred leadership behaviour.

Although an effort was made to keep the internalisation efforts unified throughout the whole organisation, the results of this study showed significant differences in the degree of internalisation amongst various units (training and operational) regarding all three factors. This can be attributed to possibly different interpretations and institutional approaches throughout the organisation and to the fact that unit managers of the different units may have applied different key value implementation approaches and practices with regard to socialisation, value induction, reinforcement of applicable value behaviour, value process alignment, and selection and orientation. In addition, certain units may have been more committed in their efforts to bring about a behavioural change in support of the values. The lack of unity has a recursive effect on the internalisation of values. The less unity there is across an organisation, the less the values will be internalised successfully. This result confirms the importance and relevance of vertical and horizontal communication throughout the organisation to create a deeper level of value understanding.

The results further indicate that many of the initiatives, although well formulated, may have lacked depth and a more aggressive approach to their implementation may have been needed. In efforts to create congruence between the organisation's implicit values and individuals' values, it is important to take into account both the cognitive and the affective desires of members of the organisation. With regard 
to the initiatives and actions taken to achieve socialisation, the results indicate that a mostly cognitive approach was followed. In view of the reported results the organisation's focus on a cognitive level of internalisation was probably one of the reasons why the interventions did not fully succeed in altering employees' current schemata (highly subjective mental or cognitive representations).

\section{Implications for practice}

The value internalisation efforts described in this article did not include role players from all levels of the organisation, and human resource (HR) practitioners wishing to contribute to more successful value internalisation efforts within a public service organisation should keep this in mind. When institutionalising a value system for an organisation, HR practitioners should attempt to create institutionalised value parity by means of a more integrated approach which involves leading role players from all organisational units as well as representatives of the larger organisation. This is particularly important for enhancing a collaborative effort to achieve a unified corporate culture within a large organisation such as one finds in the public sector. Furthermore, efforts should be made to give employees a chance to engage actively with the new values to establish value congruence.

Another shortcoming of the value internalisation efforts described in this study is that values had not been integrated into the policy and procedures of the organisation. HR practitioners should encourage leaders to facilitate the emotional-cognitive interface of employees to create a heightened state of psychological awareness and readiness to deal with the value change interface towards stronger internalisation. This can be achieved by applying a more intense socialisation framework in which the actions and implications of new value related behaviours are integrated into existing policy and procedures. A single guided valuerelated denominator such as 'creating a sense of belonging' as part of the value 'people first' can be incorporated into career and retention management strategies and practices, for example. Human resource practitioners have a responsibility to implement human resource practices which are consistent with the enforcement of value related practices. Practices could even include promotion for employees who demonstrate high value congruence.

The results of his study showed that value integration was not satisfactory for the middle and top management levels in the organisation. In the literature, leadership involvement and more specifically enactment of values have been shown to have a major impact on value internalisation efforts. Human resource practitioners should understand and support the importance of building leadership credibility in the organisation to enhance value internalisation. Firstly, word-deed alignment should be enhanced through leader participation in a more aggressive and continuous value communication campaign throughout the organisation. When leaders espouse the same values through different mediums and for different audiences, their credibility is reinforced. Secondly, public articulation by leaders of value-related interpretations contributes to a deeper level of consciousness, affecting leadership practices such as resource allocation and decision making. Thirdly, when leaders enact value behaviours according to their communicated intent, they project a stable and consistent behavioural pattern that allows for follower-leader modelling. Key leaders in the organisation can be enrolled for mentorship and coaching programmes to further their credibility. Finally, value inculcation can also be reinforced through leadership development and training. Human resource practitioners, however, should ensure that these efforts coincide with an intense, practical focus throughout the organisation. Human resource practitioners should introduce mechanisms to ensure that the transfer of learning takes place through relevant value-related practices.

\section{Limitations of the study}

This study used a quantitative approach which was an appropriate method to discover the breadth of the internalisation of values within the organisation. However, the approach was limited in the instance of this study as it did not supply reasons why the organisation's efforts failed to reach and affect all the levels within the organisation. This question could easily have been answered by a qualitative follow-up of the quantitative survey. Interviews with various role players in the organisation's efforts as well as some receivers of these efforts would have been informative and would have provided at least some answers.

\section{Conclusion}

The process and initiatives described in this article are in many ways similar to initiatives implemented in other public service organisations. A top-down approach was followed, which did not include all the levels and units within the organisation, when values were chosen for the organisation. Although a great deal of effort and time may be invested in value internalisation, this effort will not be successful if it is not tailored to the needs of the employees and not coupled with a deeper level of interpretation and internalisation throughout the organisation. The results of this study confirm the shortcomings of the top-down approach that is so often followed in public service organisations when implementing change initiatives: these initiatives do not filter through to all the different levels of the organisation and therefore remain a management goal only.

This study has revealed an important consideration for public service organisations intending to embark on efforts to build a strong value-driven organisational culture. Formulating and introducing a set of value and related actions and practices do not necessarily contribute to deeper value internalisation and inculcation. Organisations that demonstrate a deep sense of belief and conviction in support of their values are committed to far more intensely value-related practices. 


\section{Acknowledgements}

The authors would like to acknowledge Rina Owen for the statistical analyses of the data.

\section{Competing interests}

The authors declare that they have no financial or personal relationship(s) which may have inappropriately influenced them in writing this paper.

\section{Authors' contributions}

At the time of the study both authors were affiliated with the University of Pretoria. S.M. (University of Pretoria) was the study leader. A.L. (University of Pretoria) conducted the fieldwork. Both authors contributed towards the conceptualisation and writing of the article.

\section{References}

Agle, B.R., \& Caldwell, C.B. (1999). Understanding research on values in business: A level of analysis framework. Business and Society, 38(1), 326-387. http://dx.doi org/10.1177/000765039903800305

Aggerholm, H.K., Anderson, M.A., Asmuß, B., \& Thomsen, C. (2009). Management conversations in Danish Companies: Communicating corporate values and conversations in Danish Companies: Communicating corporate values and strategies. Corporate Communications: An Intern
http://dx.doi.org/10.1108/13563280910980050

Askun, D., Oz, E.U., \& Askun, O.B. (2010). Understanding managerial work values in Turkey. Journal of Business Ethics, 93, 103-114. http://dx.doi.org/10.1007/ s10551-099-0185-y

Bartlet, C.A., \& Ghoshal, S. (1994). Changing the role of top management: Beyond strategy to purpose. Harvard Business Review, 72(6), 79-88.

Begley, T.M., \& Boyd, D.P. (2000). Articulating corporate values through Human Resources Policies. Business Horizons, July-August, 8-12.

Beukman, T.L. (2005). The effect of selected variables on leadership behaviour within the framework of a transformational organisation paradigm. Unpublished doctoral thesis, University of Pretoria, Pretoria.

Brăinianu, C., \& Bălănescu, G.V. (2008). Vision, mission and corporate values: A comparative analysis of the top 50 US companies. Marketing \& Management, $3(3), 19-38$.

Booysen, L. (2001). The duality in South African leadership: Afrocentric or Eurocentric South African Journal of Labour Relations, 25(3-4), 36-64.

Cable D.M., \& Parsons, C.K. (2001). Socialization tactics and person-organization fit. Personnel Psychology, 54(1), 1-23.

Cambra-Fierro, J., Polo-Redondo, Y., \& Wilson, A. (2008). The influence of an organisation's corporate values on employees' personal buying behaviour. Journal of Business Ethics, 81, 157-167. http://dx.doi.org/10.1007/s10551-007-9486-1

Cazier, J.A., Shao, B.B.M., \& Louis, R.D.S. (2007). Sharing information and building trust through value congruence. Information Systems Frontiers, 9(5), 515-529. http://dx.doi.org/10.1007/s10796-007-9051-6

Chong, M. (2007). The role of internal communication and training in infusing corporate values and delivering brand promise: Singapore Airlines' experience. Corporate Reputation Review, 10(3), 201-212. http://dx.doi.org/10.1057/ palgrave.crr.1550051

Collins, J.C., \& Porras, J.I. (1994). Built to last: Successful habits of visionary companies. New York: Harper Collins.

Costello, A.B., \& Osborne, J.W. (2005). Best Practices in Exploratory Factor Analysis: Four Recommendations for Getting the Most From Your Analysis. Practical Assessment, Research \& Evaluation, 10(7), 1-9.

Covey, S.R. (2003). Principle-centered leadership. New York: Free Press.

Dym, B., \& Hutson, H. (2005). Leadership in nonprofit organizations. Thousand Oaks, California: Sage.

Edwards, J.R., \& Cable, D.M. (2009). The value of value congruence. Journal of Applied Psychology, 94(3), 654-677. http://dx.doi.org/10.1037/a0014891, PMid:19450005

Fenton, N.E., \& Inglis, S. (2007). A critical perspective on organisational values. Nonprofit Management \& Leadership, 17(3), 335-347. http://dx.doi.org/10.1002/ $\mathrm{nml} .153$

Field, A. (2009). Discovering Statistics with SPSS. (3rd edn.). London: Sage Publications.

Garvin, D.A., \& Roberto, M.A. (2005). Change through persuasion. Harvard Business Review, February. Retrieved February 16, 2005, from http:// harvardbusinessonline.hbsp.harvard.edu/b01/en/hbr/hbrsa/current/0502/ article/R0502F.jhtml
Grojean, M.W., Resick, C.J., Dickson, M.W., \& Smith, D.B. (2004). Leaders, values, and organizational climate: Examining leadership strategies for establishing arganizational climate regarding ethics. Journal of Business Ethics, 55(3), 223organizational climate regarding ethics. Journal of

Gruys, M.L., Stewart, S.M., Goodstein, J., Bing, M.N., \& Wicks, A.C. (2008). Values enactment in organizations: A multi-level examination. Journal of Management, 34, 806. http://dx.doi.org/10.1177/0149206308318610

Hinton, P.R., Brownlow, C., McMurray, I., \& Cozens, B. (2004). SPSS Explained. London: Routledge.

Hofstede, G.H. (1984). Culture's consequences: International differences in work related values. London: SAGE.

Hofstede, G.H. (1994). Uncommon sense about organizations: Cases, studies and field observations. London: SAGE.

Hofstede, G.H. (1997). Cultures and organizations: Software of the mind. New York: MacGraw-Hill.

Hofstede, G.H. (2001). Culture's consequences: Comparing values, behaviours, institutions and organizations across nations. Thousand Oaks, California: SAGE.

Hyde, P., \& Williamson, B. (2000). The importance of organisational values, part 3: Choosing and implementing organisational values. Focus on Change Management, 68(October), 10-14.

Kim, T., Cable, D.M., \& Kim, S. (2004). Socialization tactics, employee proactivity, and person-organization fit. Journal of Applied Psychology, 90(2), 232-241. http:// dx.doi.org/10.1037/0021-9010.90.2.232, PMid:15769234

Kline, P. (1997). An easy guide to factor analysis. London: Routledge.

Liedtka, J.M. (1989). Value congruence: The interplay of individual and organisational value systems. Journal of Business Ethics, 8(10), 805-815. http://dx.doi. org/10.1007/BF00383780

Littrell, R.F., \& Nkomo, S.M. (2005). Gender and race differences in leader behaviour preferences in South Africa. Women in Management Review, 20(8), 562-580. http://dx.doi.org/10.1108/09649420510635204

McGaw, N., \& Fabish, L. (2006). Put your values to work. Harvard Business Update, $11,3-5$.

Morginson, D. (2009). Value systems as a mechanism for organizational change. Journal of Accounting \& Organisational Change, 5(1), 7-34. http://dx.doi. org/10.1108/18325910910932197

Posner, B.Z. (2010). Another look at the impact of personal and organizational values congruency. Journal of Business Ethics, 97, 535-541. http://dx.doi.org/10.1007/ s10551-010-0530-1

Posner, B.Z., Kouzes, J.M., \& Schmidt, W.H. (1985). Shared values make a difference: An empirical test of corporate culture. Human Resource Management, 24(3), 293-309. http://dx.doi.org/10.1002/hrm.3930240305

Ren, T. (2010). Value congruence as a source of intrinsic motivation. KYKLOS, 63(1) 94-109. http://dx.doi.org/10.1111/j.1467-6435.2010.00462.x

Schein, E.H. (1990). Organisational culture. American Psychologist, 45, 109-119. http:// dx.doi.org/10.1037/0003-066X.45.2.109

Serrat, O. (2010). A primer on corporate values. Knowledge Solutions, 87, Asian Development Bank.

Simons, T. (2002). Behavioral integrity: The perceived alignment between managers' words and deeds as a research focus. Organization Science, 13(1), 18-35.

Speculand, R., \& Chaudhary, R. (2008). Living organisational values: The bridges value inculcation model. Business Strategy Series, 9(6), 324-329. http://dx.doi. org $/ 10.1108 / 17515630810923630$

Sullivan, W., Sullivan, R., \& Buffton, B. (2002). Aligning individual and organisational values to support change. Journal of Change Management, 2(3), 247. http:// dx.doi.org/10.1080/738552750

Travaglione, T., McShane, S., O'Neill, G., \& Hancock, J. (2009). The relationship between managerial values enactment, as a construct of behavioural integrity and employee trust in management. Proceedings of the eleventh internationa conference of the Society for Global and Economic Development (SGBED). Comenius University, Bratislava.

United States Air Force core values. (1997). Retrieved December 27, 2003, from http://www.usafa.af.mil/core-calue/cv--mastr.htm

Valentine, S., Godkin, L., \& Lucero, M. (2002). Ethical context, organisational commitment, and person-organisation fit. Journal of Business Ethics, 41(4), 349360. http://dx.doi.org/10.1023/A:1021203017316

Van der Wal, Z., \& Huberts, L. (2008). Value solidity in government and business: Results of an empirical study on public and private sector organisational values. The American Review of Public Administration, 38(264), 264-285. http://dx.doi. org/10.1177/0275074007309154

Van Lee, R., Fabish, L., \& McGraw, N. (2005). The value of corporate values. Strategy and Business, 39, 3-13.

Van Maanen, J., \& Schein, E.H. (1979). Toward a theory of organizational socialization. In B.M. Staw (Ed.), Research in organizational behaviour, Vol. 1 (pp. 209-264). Greenwich, Connecticut: JAI press.

Velicer, W.F., \& Jackson, D.N. (1990). Component analysis versus common factoranalysis - some further observations. Multivariate Behavioral Research, 25(1) 97-114. http://dx.doi.org/10.1207/s15327906mbr2501_12

Verquer, M.L., Beehr, T.A., \& Wagner, S.H. (2003). A meta-analysis of relations between person-organisation fit and work attitudes. Journal of Vocational Behaviour, 63, 473-489. http://dx.doi.org/10.1016/S0001-8791(02)00036-2 